\title{
Toxicity and Biological Activity of Five Plant Extracts to the Two-Spotted Spider Mite, Tetranychus urticae and Predatory Mite Amblyseius swirskii (Tetranychidae: Phytoseiidae)
}

\author{
Safaa M. Abo-Taka; M. A. Sweelam; H. M. Heikal and Iman H. Walash \\ Economic Entomol. and Agric. Zoology Dept., Fac. of Agric., Menoufia Univ., Egypt.
}

\begin{abstract}
To avoid the bad effect of synthetic insecticides, botanical products are useful tools against pests. Therefore, five plant extracts were tested to evaluate their toxicity effect against Tetranychus urticae Koch as pest and its predatory mite Amblyseius swirskii Athias-Henroit. These plants are red pepper, garlic, seena-L, galls, and thyme. The effect of plant extracts on some biological aspects of $T$. urticae was studied. Five concentrations of each extract were used 1, 2, 3, 5 and $6 \%$. $\mathrm{LC}_{50}$ of both field and susceptible strain was calculated, in addition to slope and tolerance ratio. The effect of $\mathrm{LC}_{50}$ and $\mathrm{LC}_{30}$ of field strain on some biological aspects was studied. Red pepper extract exhibited a high degree of efficiency against adult female of $T$. urticae with overall mean mortality ranged from $24.46-98.56 \%$; while the lowest was thyme recorded overall mean mortality ranged from 0.00 to $66.86 \%$ for 1 to $6 \%$ concentrations, respectively. As for predator A. swirskii overall mean mortality of red pepper was the highest recording 33.99 to $89.52 \%$ with $1.29 \% \mathrm{LC}_{50}$, whilst galls and thyme extracts recorded the least mortality. There are significant differences between red pepper and other extracts in incubation period; where mean of incubation period was 7.27 ; while there are no significant differences between the other four plant extracts. Duration of larval stage was prolonged to 6 days in red pepper treatment. All hatched larvae died in garlic treatment and can't develop to protonymph. Females in red pepper treatments can't deposit eggs and died, while life cycle was prolonged to $14.75,15.97$, and 15.79 days for galls, thyme, seena-L, respectively in comparison with 10.47 days in control. $\mathrm{LC}_{30}$ of tested plant extracts prolonged incubation period of $T$. urticae especially in red pepper and garlic treatments, in comparison with control. Garlic and red pepper extracts registered the longest period of life cycle compared with control 10.4 days. Females at garlic treatment died after 6 days without laying eggs, while males lived for five days then died. Female longevity was shortened to 10.89 days in red pepper comparing with 14.67 days in untreated females. Furthermore, few eggs were laid in all treatments in comparison with control.
\end{abstract}

Key Words: Amblyseius swirskii, Tetranychus urticae, Toxicity, Bioassay, botanical products.

\section{INTRODUCTION}

Problems associated with the use of synthetic insecticides led researchers to look for natural plant protection compounds such as botanical insecticides and antifeedants. Botanical products are useful tools in many pest management programs because they are effective and specifically target plants natural enemies (Isman, 2006). Tetranychus urticae Koch is a phytophagous pest that can cause significant yield losses in many agricultural crops, including fruits, cotton, vegetables, and ornamentals (Stumpf et al., 2001 and Van Leeuwen et al., 2007). This mite has been reported to attack about 1200 species of plants, of which more than 150 are economically significant (Zhang, 2003). Unfortunately, spider mite has developed resistance to most available pesticides and the loss of acaricidal efficacy, as a result of resistance mite populations in the major problem, encountered (Ay, 2005). Currently, the cost of their use to counter spider mite damage exceeds USD \$1 billion per year in the European Union. Due to the excessive use of pesticides and the associated problems of resistance and environmental pollution, there is an increasing demand for sustainable, environmentally friendly control methods. In addition, control methods based on the use of synthetic acaricides sometimes fail to keep the number of spider mites below economic threshold levels (Tirello et al., 2012). It is, therefore crucial search was done to find new selective pesticides compatible with the use of natural enemies that can minimize negative effects on the environment, including both fauna and flora (Steiner et al., 2011). The acaricidal activity of Lavandula officinalis against two-spotted spider mite at different concentrations may be attributed to the major plant constituents (Heikal et al., 2012). The use of some plant extracts can present a realistic alternative to synthetic acaricides because of their efficiency against pests. For example, when used as pesticides, plant extracts can affect pest behavior, including repelling the pest or prohibiting feeding activity, and pest physiology, including molting and respiratory inhibition, growth and fecundity reduction, and also cuticle disruption (Isman, 2000; Enan, 2001 and Gokce et al., 2011). Moreover, exposure to varying mixtures of bio- synthetically different compounds found in plant extracts can delay the evolution of resistance (Isman, 2000). Plant extracts are also an environmentally interesting tool because of their biodegradability and minimal side-effects on nontarget organisms as well as on the environment (Isman, 2000, 2001 \& 2004; Basta and Spooner-Hart, 2002; Flamini, 2003 \& 2006; Rasikari et al., 2005; Tewary et al., 2005; Pontes et al., 2007 \& 2010; Cavalcanti et al., 2010 and Attia et al., 2011,2012a \& 2012b). Also, Geng et al., 2014 mentioned that garlic straw or extracts form have potential uses for 
the sustainable management of $T$. urticae and $T$. viennensis. Many predaceous mites are now used as biological control agents and are important in IPM programs. Amblyseius swirskii Athias-Henriot is one of the most important generalist indigenous predators of tetranychid mite. Recently, the extracts of plants have proved interest as sources of natural products (Kotb, 2003).

In the present study, the toxicity effect of five plant extracts (red pepper, garlic, seena-L, galls, and thyme) on adult females of both $T$. urticae and $A$. swirskii was studied. The effects of both $\mathrm{LC}_{50}$ and $\mathrm{LC}_{30}$ on incubation period, duration of immature stages, female longevity, and number of laid eggs per female were also studied.

\section{MATERIALS AND METHODS}

\section{Mite sources and rearing technique: \\ 1.1. Tetranychus urticae:}

The used strain of T. urticae, Koch was originated from infested castor oil leaves, Ricinus communis, cultivated at Shebin Elkom locality, rearing was carried out in potted beans Phaseolus vulgaris L. cultivated in an isolated compartment $1.5 \mathrm{~m} \times 2 \mathrm{~m}$ in the experimental greenhouse for feeding the predatory mite in addition to susceptible strain which has been reared in the absence of chemicals under laboratory conditions for one year, where infested castor oil leaves were put in $250 \mathrm{ml}$ jars filled with tap waters. The dry leaves were replaced with new clean ones, in addition to exchange water every $3-7$ days.

\subsection{Amblyseius swirskii}

The predatory mite $A$. swirskii was collected from hibiscus plants, Hibiscus rosa sinensis and reared in plastic pans $30 \times 20 \times 7 \mathrm{~cm}$, where saturated cotton pads were put in the middle of each pan, leaving a space provided with water as a barrier to prevent mites from escaping, leaves of Hibiscus were established on cotton pads where the predatory mite was reared, infested bean leaves with $T$. urticae were daily provided as a source of food. Pans were kept in laboratory at $25 \pm 2^{\circ} \mathrm{C}$ and $60 \pm 10 \%$ R.H.

\section{Plant extracts used}

Five plants were chosen to be extracted by aqueous method where dry powders of these plants was added to $200 \mathrm{ml}$ autoclaved Sabouraud medium before solidification and mixed thoroughly. Sabouraud medium was previously autoclaved with steam under pressure at $121{ }^{\circ} \mathrm{C}$ for $20 \mathrm{~min}$. Five concentrations of each aqueous extract, i.e. $1,2,3,5$, and $6 \%$ were prepared. The aqueous extracts were kept for further tests (Mutwally et al., 2002). Used plants are: galls (Quercus infectoria), seena-L (Cassia senna), red pepper (Capsicum annum), garlic (Allium sativum) and thyme (Thymus vulgaris).

\section{Growing field strain}

\subsection{Field strain of Tetranychus urticae}

About $30 \mathrm{~m}^{2}$ was cultivated with Phaseolus vulgaris $\mathrm{L}$. The area was divided into six plots for 5 plant extracts and control. After ten days highly artificial infestation was done to increase the population of Tetranychus urticae, then plots were sprayed with different plant extracts $3 \%$, another spray with the obvious five plant extracts for each plot was done after one, two, and three weeks to allow tolerance to grow as field strain. Then after another two weeks, from each plot, $T$. urticae adult females were used to study the toxicity of different concentrations of each plant extract on the field strain of the same plant extract comparing with laboratory susceptible strain.

\subsection{Field strain of Amblyseius swirskii}

Six plastic pans $30 \times 20 \times 7$ of reared $A$. swirskii were sprayed weekly with each plant extract at $3 \%$ concentration. Control was sprayed with water, the spray was repeated for each material and with the same concentration after one, two and three weeks, the resulted strain considered field and used to determine the toxicity of different plant extracts on $A$. swirskii, where it was kept under open green house in the field, leaves of Hibiscus were replaced with new ones when dry, T. urticae was provided every day as a source of food.

\section{Toxicity tests and preparation of concentrate - mortality lines of tested plant extracts:}

The leaf-spray method (El-Defrawi et al., 1965 and Abo-Shabana, 1980) was applied to test the susceptibility of field strain of $T$. urticae and $A$. swirskii to five different plant extracts compared with susceptible strain. Four castor-oil bean leaf discs (2 $\mathrm{cm}$ diameter) were placed on moist cotton pad in Petri dish $(9 \mathrm{~cm}$ in diameter) which represents as four replicates for each concentration of different plant extracts. Ten adult female of $T$. urticae were transferred to each leaf-disc before spraying with plant extract solution. The discs carrying mites were sprayed with different concentrations using a manual atomizer, concentrations were calculated as percentages on the basis of crude material. Five concentrations were selected for each material to give a proper dosage mortality line. Control checks were sprayed with water. The treated adult females were kept under laboratory conditions and examined daily for one week. The dead mites were counted, and mortality percentages were calculated and corrected using Abbott's formula (Abbott, 1925). To determine 
the toxicity of five plant extracts to adult female of $T$. urticae laboratory strain was reared for two years in the laboratory without exposure to any chemicals, spraying technique was used. Slope, $\mathrm{LC}_{50}$ and $95 \%$ fiducial limits were estimated by probit analysis program (PROBAN) (Jedrychowski, 1991). Susceptible strain of $T$. urticae which reared laboratory without exposure to any chemicals for two years, $L C_{50}$ values were compared with all results of field strain, the tolerance ratio was determined according to Georghiou (1972): Tolerance ratio (TR) $=\mathrm{LC}_{50}$ for field strain $/ \mathrm{LC}_{50}$ for susceptible strain. The same technique was followed for the predatory mite, A. swirskii, using only the field strain.

\section{Effect of selection pressure on the biology of Tetranychus urticae:}

\subsection{Effect of $\mathrm{LC}_{50}$ :}

The five plant extracts (red pepper, garlic, seena$\mathrm{L}$, galls and thyme) were used to determine the effect of $\mathrm{LC}_{50}$ concentration on different biological aspects of T. urticae. Seven adult females and three males of T. urticae were transferred to each leaf-disc of castoroil leaves and placed on cotton pad in a $9 \mathrm{~cm}$ diameter Petri-dishes which saturated with water, four replicates were used. The leaf disc spray method was used. The incubation period of T. urticae eggs and the duration of survival stages were studied. Control was sprayed with water. Discs were examined twice daily and discs were changed when it wilt.

\subsection{Effect of $\mathbf{L C}_{30}$ :}

The selective pressure with $\mathrm{LC}_{50}$ of the chosen five plant extracts was high toxic for Tetranychus urticae, where all survival females can't deposit eggs and died after maximum six days, therefore $\mathrm{LC}_{30}$ of these materials was used to study the duration of immature stages, in addition to adult longevity, also the fecundity of treated females was studied. All experiments were carried out under $25 \pm 2{ }^{\circ} \mathrm{C}$ and 60 $\pm 10 \%$ relative humidity.

\section{6- Statistical analysis:}

Data were analyzed by the computer using the CoStat 6.400 (2008) Statistical CoHort Software program, Copyright (C) 1998- 2008 CoHort Software 798 Lighthouse Ave. PMB 320 Monterey CA, 93940 USA, using ANOVA test with LSD 5\% and the Mean \pm SE.

\section{RESULTS AND DISCUSSION}

\section{Toxicity of different plant extracts to the adult} female of:

\subsection{Tetranychus urticae:}

Results in Table (1) proved that red pepper extract exhibited a high degree of efficiency against adult female of T. urticae recording overall mean of mortality ranged from $24.46-98.56 \%$, while $1 \%$ concentration caused $40.70 \%$ mortality after 7 days but $3 \%$ concentration caused 46.6 after 24 hours of application increased to $83.93 \% 7$ days after application where 5, $6 \%$ caused 76.6 and $93.3 \%$ mortality after one day increased to $100 \%$ after 5 and 3 days of application for 5 and $6 \%$ concentrations, respectively. As for garlic, the mortality after one day of application increased by increasing concentration from 6.6 ( $1 \%$ conc.) to $63.3 \%$ (6\% conc.); while these mortalities were highest after 7 days for 3,5 , $6 \%$ concentrations $(80.7,93.7$, and $100 \%$ mortality). Seena-L and galls have approximately the same effect on Tetranychus urticae which less than red pepper and garlic, where mortality after 7 days was about 50 $\%$ for 1 and $2 \%$ concentrations increased to reach 100 $\%$ only when $6 \%$ used. The least toxic plant extract was thyme where overall mean ranged from $0: 66: 86$ $\%$ with about $50 \%$ mortality for 1,2 , and $3 \%$ concentrations after 7 days of application; while 5,6 $\%$ concentrations recorded $66.6 \%$ and $96.5 \%$, respectively. Slope, $\mathrm{LC}_{50}$ and $95 \%$ fiducial limits of $\mathrm{LC}_{50}$ are shown in Table (2). The $\mathrm{LC}_{50}$ values of these materials were $1.2671,1.3815,1.8360,2.8192$, and $3.0923 \%$ for red pepper, garlic, seena-L, galls, and thyme, respectively. Comparing the slope values, galls showed the lowest slope 0.2325 followed by seena-L 0.5578 , thyme 0.7431 , garlic 0.8120 , and red pepper 0.9223 , respectively.

Data in Table (2) revealed that susceptible strain which reared laboratory for two years recorded $\mathrm{LC}_{50}$ values of $0.41,0.33,0.38,0.57$, and $1.48 \%$ for red pepper, garlic, seena-L, galls, thyme, respectively, when field strain was compared with susceptible strains, results revealed that the tolerance ratio for these materials were $3.09,4.19,4.90,5.03$, and 2.09, respectively.

The foregoing results cleared that garlic plant extract was the most effective compound on the susceptible strain of Tetranychus urticae where $\mathrm{LC}_{50}$ was $0.3342 \%$ followed by red pepper where $\mathrm{LC}_{50}$ for susceptible strain was $0.4121 \%$, on the other hand red pepper was more toxic on field strain than garlic, $\mathrm{LC}_{50}$ after 7 days were $1.2671,1.3815 \%$ for red pepper and garlic, respectively. These results are in agreement with those obtained by Boyd and Alverson (2000), Antonious et al. (2007), and Potenza et al. (1999) who reported that garlic control $T$. urticae satisfactory; Nour El-Deen and Abdallah (2013) who found that garlic $2.5 \mathrm{ml} / \mathrm{L}$ caused $54 \%$ mortality for T. urticae after 7 days of application.

\subsection{Amblyseius swirskii:}

The same five plant extracts were tested in the laboratory to determine their effect on the adult 
Table (1): Toxicity effect of plant extracts on field strain of Tetranychus urticae adult female

\begin{tabular}{|c|c|c|c|c|c|c|c|c|c|}
\hline \multirow{2}{*}{ Plant extract } & \multirow{2}{*}{$\begin{array}{c}\text { Conc. } \\
\%\end{array}$} & \multicolumn{7}{|c|}{$\%$ Mortality after } & \multirow{2}{*}{ Overall mean } \\
\hline & & 1 day & $2 d$ & $3 \mathrm{~d}$ & $4 \mathrm{~d}$ & $5 \mathrm{~d}$ & $6 \mathrm{~d}$ & $7 \mathrm{~d}$ & \\
\hline \multirow{5}{*}{ Red pepper } & 1 & 10.3 & 14.6 & 17.9 & 26.8 & 28.0 & 32.9 & 40.70 & 24.46 \\
\hline & 2 & 21.3 & 28.6 & 34.9 & 54.9 & 60.3 & 70.9 & 73.5 & 49.20 \\
\hline & 3 & 46.6 & 53.2 & 66.5 & 73.1 & 76.4 & 77.7 & 83.93 & 68.18 \\
\hline & 5 & 76.6 & 83.2 & 93.2 & 99.8 & 100 & 100 & 100 & 93.26 \\
\hline & 6 & 93.3 & 96.6 & 100 & 100 & 100 & 100 & 100 & 98.56 \\
\hline \multirow{5}{*}{ Garlic } & 1 & 6.6 & 10.3 & 12.6 & 23.3 & 26.3 & 26.3 & 31.0 & 12.63 \\
\hline & 2 & 12.3 & 22.9 & 35.6 & 43.9 & 58.4 & 62.5 & 70.4 & 43.71 \\
\hline & 3 & 16.6 & 29.9 & 46.5 & 59.8 & 73.1 & 79.9 & 80.7 & 55.21 \\
\hline & 5 & 46.6 & 53.2 & 66.5 & 83.1 & 93.1 & 93.7 & 93.7 & 67.30 \\
\hline & 6 & 63.3 & 69.9 & 86.5 & 99.8 & 100 & 100 & 100 & 88.50 \\
\hline \multirow{5}{*}{ Seena-L } & 1 & 4.0 & 7.9 & 10.3 & 10.3 & 10.3 & 10.6 & 13.3 & 9.53 \\
\hline & 2 & 11.3 & 22.9 & 31.0 & 38.9 & 39.0 & 42.6 & 50.6 & 33.76 \\
\hline & 3 & 16.6 & 36.6 & 49.9 & 59.9 & 63.5 & 63.5 & 63.5 & 49.04 \\
\hline & 5 & 46.6 & 63.2 & 70.5 & 70.5 & 70.8 & 70.8 & 97.4 & 69.79 \\
\hline & 6 & 60.3 & 73.3 & 83.3 & 96.6 & 99.9 & 100 & 100 & 87.63 \\
\hline \multirow{5}{*}{ Galls } & 1 & 0 & 0 & 0 & 0 & 0 & 0 & 0 & 0.0 \\
\hline & 2 & 5.6 & 11.3 & 15.6 & 22.3 & 31.0 & 41.6 & 43.0 & 24.34 \\
\hline & 3 & 13.3 & 23.3 & 33.3 & 43.3 & 46.6 & 65.6 & 63.2 & 41.23 \\
\hline & 5 & 33.3 & 43.3 & 53.3 & 63.3 & 66.6 & 76.6 & 76.2 & 50.81 \\
\hline & 6 & 53.3 & 69.9 & 83.2 & 96.5 & 99.8 & 100 & 100 & 86.07 \\
\hline \multirow{5}{*}{ Thyme } & 1 & 0 & 0 & 0 & 0 & 0 & 0 & 0 & 0.00 \\
\hline & 2 & 6.2 & 8.6 & 11.2 & 22.6 & 22.8 & 25.8 & 31.6 & 18.40 \\
\hline & 3 & 10 & 20 & 26.6 & 33.2 & 43.2 & 49.8 & 53.1 & 33.70 \\
\hline & 5 & 23.3 & 36.6 & 43.2 & 59.8 & 63.1 & 66.4 & 66.6 & 51.29 \\
\hline & 6 & 26.6 & 36.6 & 53.2 & 73.2 & 86.5 & 96.5 & 96.5 & 66.86 \\
\hline
\end{tabular}

Table (2): $\mathrm{LC}_{50}$, slope and tolerance ratio of some plant extracts after seven days of spraying on Tetranychus urticae adult females

\begin{tabular}{|c|c|c|c|c|c|c|}
\hline \multirow{2}{*}{ Plant extract } & \multicolumn{2}{|c|}{$\mathrm{LC}_{50}$} & \multirow{2}{*}{ Slope \pm SE } & \multicolumn{2}{|c|}{ Fiducial limits $95 \%$ of $\mathrm{LC}_{50}$} & \multirow{2}{*}{$\begin{array}{c}\text { Tolerance Ratio } \\
\text { (TR) }\end{array}$} \\
\hline & Field strain & Susceptible strain & & lower & Upper & \\
\hline Red pepper & 1.2671 & 0.4121 & $0.92 \pm 0.22$ & 1.8460 & 1.9711 & 3.08 \\
\hline Garlic & 1.3815 & 0.3342 & $0.81 \pm 0.22$ & 1.1887 & 1.5969 & 4.13 \\
\hline Seena-L & 1.8360 & 0.3831 & $0.56 \pm 0.26$ & 1.6004 & 2.0963 & 4.79 \\
\hline Galls & 2.8192 & 0.5645 & $0.23 \pm 0.19$ & 2.4903 & 3.1826 & 4.99 \\
\hline Thyme & 3.0923 & 1.4827 & $0.74 \pm 0.38$ & 2.7373 & 3.4859 & 2.09 \\
\hline
\end{tabular}

Table (3): Toxicity effect of some plant extracts on field strain of Amblyseius swirskii adult females

\begin{tabular}{|c|c|c|c|c|c|c|c|c|c|}
\hline \multirow{2}{*}{ Plant extracts } & \multirow{2}{*}{$\begin{array}{c}\text { Conc. } \\
\%\end{array}$} & \multicolumn{7}{|c|}{ Mortality $\%$ after } & \multirow{2}{*}{$\begin{array}{c}\text { Overall mortality } \\
\%\end{array}$} \\
\hline & & 1 day & $2 \mathrm{~d}$ & $3 \mathrm{~d}$ & $4 d$ & $5 \mathrm{~d}$ & $6 \mathrm{~d}$ & $7 \mathrm{~d}$ & \\
\hline \multirow{5}{*}{ Red pepper } & 1 & 22.66 & 28.66 & 32.2 & 35.2 & 35.6 & 40.3 & 43.3 & 33.99 \\
\hline & 2 & 35.66 & 41.3 & 47.6 & 55.6 & 60.3 & 60.3 & 62.6 & 51.91 \\
\hline & 3 & 40.00 & 35.33 & 60.00 & 73.33 & 80.33 & 80.00 & 80.33 & 64.19 \\
\hline & 5 & 56.66 & 66.66 & 80.00 & 83.33 & 86.66 & 86.66 & 86.66 & 78.09 \\
\hline & 6 & 66.66 & 76.66 & 86.66 & 96.66 & 100 & 100 & 100 & 89.52 \\
\hline \multirow{5}{*}{ Garlic } & 1 & 5.7 & 13.3 & 18.6 & 25.6 & 35.3 & 41.0 & 41.3 & 25.89 \\
\hline & 2 & 19.7 & 21.3 & 32.3 & 42.6 & 51.0 & 60.3 & 64.0 & 41.6 \\
\hline & 3 & 13.33 & 23.33 & 36.33 & 50.00 & 56.66 & 66.66 & 80.0 & 43.76 \\
\hline & 5 & 36.33 & 46.66 & 63.33 & 76.66 & 86.66 & 96.60 & 97.00 & 71.89 \\
\hline & 6 & 46.66 & 60.00 & 66.66 & 80.00 & 90.00 & 96.66 & 100 & 77.14 \\
\hline \multirow{5}{*}{ Seena-L } & 1 & 6.7 & 13.3 & 15.3 & 22.6 & 30.3 & 36.3 & 37.3 & 31.68 \\
\hline & 2 & 10.66 & 18.4 & 21.6 & 32.3 & 45.3 & 61.6 & 66.0 & 36.55 \\
\hline & 3 & 13.33 & 26.66 & 36.66 & 50.00 & 60.00 & 73.33 & 73.33 & 47.66 \\
\hline & 5 & 23.33 & 33.33 & 46.66 & 56.66 & 70.00 & 83.33 & 93.33 & 58.09 \\
\hline & 6 & 30.00 & 43.33 & 56.66 & 66.66 & 83.33 & 90.0 & 100 & 67.14 \\
\hline \multirow{5}{*}{ Galls } & 1 & 5.6 & 10.6 & 12.7 & 15.9 & 16.3 & 16.3 & 16.3 & 13.39 \\
\hline & 2 & 5.3 & 15.6 & 20.3 & 22.3 & 36.6 & 36.6 & 37.00 & 24.81 \\
\hline & 3 & 10.00 & 20.00 & 33.33 & 46.66 & 56.66 & 60.00 & 60.00 & 40.95 \\
\hline & 5 & 23.33 & 33.33 & 43.33 & 56.66 & 70.00 & 76.66 & 76.76 & 54.29 \\
\hline & 6 & 26.66 & 36.66 & 50.00 & 56.66 & 76.66 & 83.33 & 83.33 & 59.04 \\
\hline \multirow{5}{*}{ Thyme } & 1 & 0.00 & 2.23 & 4.33 & 4.66 & 6.33 & 6.33 & 8.67 & 4.65 \\
\hline & 2 & 2.00 & 5.60 & 8.33 & 12.00 & 21.00 & 22.67 & 22.67 & 13.47 \\
\hline & 3 & 20.00 & 26.00 & 36.66 & 50.00 & 56.66 & 63.33 & 63.33 & 45.14 \\
\hline & 5 & 25.6 & 38.7 & 45.6 & 59.3 & 72.3 & 74.0 & 74.0 & 55.21 \\
\hline & 6 & 39.3 & 49.7 & 59.7 & 69.2 & 78.6 & 86.6 & 89.6 & 66.53 \\
\hline
\end{tabular}


female of $A$. swirskii which reared laboratory after exposure to $3 \%$ of each plant extract three times.

Results obtained in Tables ( 3 and 4) show the mortality of $A$. swirskii after spraying five plant extracts. Five concentrations were used 1, 2, 3, 5, and $6 \%$ for seven days. Overall mean mortality of red pepper was the highest recording 33.99 to $89.52 \%$ with $1.29 \% \mathrm{LC}_{50}$, followed by garlic where $6 \%$ concentration recorded only $77.14 \%$ overall mean mortality where $\mathrm{LC}_{50}$ was $1.36 \%$. Seena-L plant extract recorded overall mean of $31.68 \%$ for $1 \%$ concentration and increased gradually to $67.14 \%$ for $6 \%$ concentration. Galls and thyme extracts recorded the least mortality of this group, where $1 \%$ concentration gave $13.39,4.65 \%$, while $6 \%$ gave $59.04 \%$ and $66.53 \%$ as overall mortality for galls and thyme, respectively.

As for slope Table (4) results showed that galls extract have high slope 0.91 comparing with other plant extracts; while garlic have the lowest 0.25 .

As for the predatory mite, Amblyseius swirskii, it could be stated that red pepper was the most effective plant extract on both susceptible and field strain followed by garlic. It was mentioned that $T$. urticae females tolerate garlic, seena-L, and galls than red pepper and thyme; while $A$. swirskii females tolerate galls, seena-L and red pepper than garlic and thyme therefore red pepper was mentioned as more promising compound where the predator have high tolerance rate with low tolerance rate on the prey, $T$. urticae.

\section{Effect of $\mathbf{L C}_{50}$ and $\mathbf{L C}_{30}$ on some biological aspects of Tetranychus urticae: \\ 2.1. Effect of $\mathbf{L C}_{50}$ :}

Data in Table (5) cleared that plant extracts prolonged incubation period of eggs with significant difference between control and other treatments, also there are significant difference between incubation period of red pepper and other treatments, where mean of incubation period was $7.27 \pm 0.37$ days; while there are no significant difference between the other four plant extracts where incubation period ranged between $5.79-5.29$ days. Where larvae were treated with plant extracts, data showed that duration of larval stage was prolonged to 6 days in red pepper treatment; while the mean of larval stage was 4.5 , 5.25 , and 5.0 days for galls, thyme, and seena-L, respectively. All hatched larvae died in garlic treatment and can't develop to protonymph; while this duration was only $2.4 \pm 0.31$ days for untreated control. Statistical analysis showed significant difference between control and other treatments. Protonymph duration prolonged 3 days for the four plant extracts; while this duration was 2.27 days in untreated control without significant differences.

Survived deutonymph was only two days in red pepper, galls, seena-L, and 2.25 days for thyme; while in untreated control it was prolonged to $2.47 \pm 0.23$ days without significant differences. Total immature duration ranged between 9.5 to 11.0 days for different plant extract treatments; while it was only $7.14 \pm 0.49$ days in control.

Regarding the life cycle, as in garlic treatment, females in red pepper treatments can't deposit eggs and died after while and the mean duration of life cycle was prolonged to $14.75 \pm 0.95,15.97 \pm 1.02$, and $15.79 \pm 1.30$ days for galls, thyme, seena-L, respectively, in comparison to $10.47 \pm 1.15$ days in control. Statistical analysis showed that no significant differences between life cycle duration in treated individuals but there was significant difference, in the life cycle period, between plant extracts and control. As for the effect of plant extracts on the biology of $T$. urticae, the obtained results cleared that spraying $\mathrm{LC}_{30}$ of different plant extracts, reduced the number of laid eggs comparing with control. In this respect, few authors studied the toxicity of some plant extracts on Tetranychus urticae and Euseius scutalis Kotb (2003).

\subsection{Effect of $\mathrm{LC}_{30}$ :}

As shown in Table (6) spraying $\mathrm{LC}_{30}$ of tested plant extracts prolonged incubation period of Tetranychus urticae especially in red pepper and garlic treatment, where the mean of this period was 5.54 and 4.58 days, while it shortened to $3.60,3.10$ and 3.10 days for galls, thyme, and seena-L, respectively comparing with 3.10 days in untreated control. Statistical analysis showed significant difference between red pepper, garlic and other treatments including control.

It could be concluded that red pepper and garlic have clear effect in prolonging incubation period of T. urticae egg. The duration of larval stage on treatments is different where garlic and galls registered the longest period 4.67, 4.13 days; while it was 3.2 and 3.0 days for thyme and red pepper, the shortest period was observed in seena-L 2.63 days compare with 2.4 days for untreated. Protonymph duration was 3.46, 3.00 days for red pepper and garlic without significant difference between them, but the difference was significant with other treatments including control. Deutonymphal stage ranged from 2.20 to 2.69 days in all treatments including untreated without significant differences.

Laboratory tests were conducted to evaluate the effect of $\mathrm{LC}_{30}$ of five plant extracts on adult stage of 
Table (4): $\mathrm{LC}_{50}$, slope and tolerance ratio of some plant extracts after seven days of spraying on Amblyseius swirskii adult females

\begin{tabular}{|c|c|c|c|c|c|c|}
\hline \multirow[b]{2}{*}{$\begin{array}{l}\text { Plant } \\
\text { extract }\end{array}$} & \multicolumn{2}{|c|}{$\mathrm{LC}_{50}$} & \multirow[b]{2}{*}{$\begin{array}{l}\text { Slope } \pm \\
\text { SE }\end{array}$} & \multicolumn{2}{|c|}{ Fiducial limits $95 \%$ of $\mathrm{LC}_{50}$} & \multirow[b]{2}{*}{$\begin{array}{l}\text { Tolerance } \\
\text { Ratio (TR) }\end{array}$} \\
\hline & Field strain & $\begin{array}{c}\text { Susceptible } \\
\text { strain }\end{array}$ & & Lower & Upper & \\
\hline Red pepper & 1.29 & 0.3142 & $0.36 \pm 0.20$ & & & 4.09 \\
\hline Garlic & 1.36 & 0.3821 & $0.25 \pm 0.21$ & 1.0182 & 1.6630 & 3.57 \\
\hline Seena-L & 1.52 & 0.2934 & $0.34 \pm 0.21$ & 1.1269 & 1.8743 & 5.19 \\
\hline Galls & 2.47 & 0.4076 & $0.91 \pm 0.22$ & 1.9585 & 3.0265 & 6.07 \\
\hline Thyme & 4.98 & 1.5234 & $0.70 \pm 0.24$ & 3.6572 & 7.6013 & 3.27 \\
\hline
\end{tabular}

Table (5): Effect of $\mathrm{LC}_{50}$ treatment of five plant extracts on some biological aspects of Tetranychus urticae at $25^{\circ} \mathrm{C}$ and $60 \% \mathrm{RH}$

\begin{tabular}{ccccccc}
\hline \multirow{2}{*}{ Plant extract } & \multicolumn{5}{c}{ Duration on days } \\
\cline { 2 - 7 } Garlic & Incubation period & larvae & protonymph & deutonymph & immature & Life cycle \\
\hline Red pepper & $7.33 \pm 0.47^{\mathrm{b}}$ & - & - & - & - & - \\
\hline Seena-L & $5.27 \pm 0.37^{\mathrm{a}}$ & $6.0 \pm 0.89^{\mathrm{a}}$ & $3.0 \pm 0.76^{\mathrm{a}}$ & $2.0 \pm 0.44^{\mathrm{a}}$ & $11.0 \pm 1.26^{\mathrm{a}}$ & - \\
\hline Galls & $5.29 \pm 0.64^{\mathrm{b}}$ & $\begin{array}{c}4.50 \pm \\
0.41^{\mathrm{a}}\end{array}$ & $3.0 \pm 0.76^{\mathrm{a}}$ & $2.0 \pm 0.44^{\mathrm{a}}$ & $9.5 \pm 1.13^{\mathrm{b}}$ & $14.75 \pm 0.95^{\mathrm{a}}$ \\
\hline \multirow{2}{*}{ Thyme } & $5.47 \pm 0.42^{\mathrm{b}}$ & $\begin{array}{c}5.25 \pm \\
0.58^{\mathrm{a}}\end{array}$ & $3.0 \pm 0.76^{\mathrm{a}}$ & $2.25 \pm 0.48^{\mathrm{a}}$ & $10.50 \pm 1.47^{\mathrm{ab}}$ & $15.97 \pm 1.02^{\mathrm{a}}$ \\
\hline Control & $3.33 \pm 0.47^{\mathrm{c}}$ & $2.40 \pm 0.31^{\mathrm{b}}$ & $2.27 \pm 0.39^{\mathrm{a}}$ & $2.47 \pm 0.23^{\mathrm{a}}$ & $7.14 \pm 0.49^{\mathrm{c}}$ & $10.47 \pm 1.15^{\mathrm{b}}$ \\
\hline L.S.D. 5\% & 1.58 & 2.0 & 0.81 & 0.49 & 1.28 & 1.00 \\
\hline
\end{tabular}

*Values in each column followed by different letter(s) are significantly different at $5 \%$ level.

Table (6): Effect of $\mathrm{LC}_{30}$ treatment of five plant extracts on some biological aspects of Tetranychus urticae at $25^{\circ} \mathrm{C}$ and $60 \% \mathrm{RH}$

\begin{tabular}{|c|c|c|c|c|c|c|c|c|c|c|}
\hline \multirow{3}{*}{$\begin{array}{l}\text { Plant } \\
\text { extract }\end{array}$} & \multicolumn{10}{|c|}{ Duration in days } \\
\hline & \multirow{2}{*}{$\begin{array}{c}\text { Incubation } \\
\text { period }\end{array}$} & \multirow[b]{2}{*}{ larvae } & \multirow[b]{2}{*}{ Protonymph } & \multirow[b]{2}{*}{ Deutonymph } & \multirow{2}{*}{ Immature } & \multirow{2}{*}{ life cycle } & \multicolumn{2}{|c|}{ longevity } & \multirow{2}{*}{$\begin{array}{r}\text { no. of } \\
\mathrm{egg} / \mathrm{P}\end{array}$} & \multirow{2}{*}{$\begin{array}{l}\text { Daily rate } \\
\text { of ovi. / } 9 \\
\end{array}$} \\
\hline & & & & & & & 오 & $\delta$ & & \\
\hline Garlic & $4.58 \pm 0.67^{b}$ & $4.67 \pm 0.67^{\mathrm{a}}$ & $3.00 \pm 0.62^{\mathrm{a}}$ & $2.50 \pm 0.30^{\mathrm{a}}$ & $10.17 \pm 0.88^{\mathrm{a}}$ & $14.75 \pm 1.94^{\mathrm{a}}$ & $*$ & 5.0 & - & - \\
\hline Red pepper & $5.54 \pm 0.73^{\mathrm{a}}$ & $3.00 \pm 0.67^{b}$ & $3.46 \pm 0.69^{\mathrm{a}}$ & $2.69 \pm 0.20^{\mathrm{a}}$ & $9.15 \pm 1.21^{\mathrm{ab}}$ & $14.69 \pm 2.01^{\mathrm{a}}$ & 10.9 & 5.7 & $20.22^{\mathrm{c}}$ & 3.25 \\
\hline Seena-L & $3.10 \pm 0.44^{\mathrm{c}}$ & $2.63 \pm 0.81^{\mathrm{b}}$ & $2.88 \pm 0.79^{\mathrm{a}}$ & $2.67 \pm 0.47^{\mathrm{a}}$ & $8.18 \pm 0.76^{\mathrm{bc}}$ & $11.28 \pm 1.29^{\mathrm{bc}}$ & 13.7 & 9.0 & $23.82^{\mathrm{c}}$ & 3.25 \\
\hline Galls & $3.60 \pm 0.44^{c}$ & $4.13 \pm 0.85^{\mathrm{a}}$ & $2.33 \pm 0.25^{b}$ & $2.20 \pm 0.85^{\mathrm{a}}$ & $8.66 \pm 0.97^{b}$ & $12.26 \pm 2.12^{b}$ & 11.4 & 10.0 & $28.80^{\mathrm{b}}$ & 4.0 \\
\hline Thyme & $3.10 \pm 0.44^{c}$ & $3.20 \pm 0.77^{b}$ & $2.50 \pm 1.02^{\mathrm{b}}$ & $2.44 \pm 0.76^{\mathrm{a}}$ & $8.14 \pm 0.76^{\mathrm{bc}}$ & $11.24 \pm 0.88^{\mathrm{bc}}$ & 11.3 & 8.8 & $13.21^{\mathrm{d}}$ & 2.33 \\
\hline Control & $3.10 \pm 0.44^{\mathrm{c}}$ & $2.40 \pm 0.26^{\mathrm{b}}$ & $2.2 \pm 0.31^{\mathrm{b}}$ & $2.50 \pm 0.21^{a}$ & $7.1 \pm 0.77^{\mathrm{c}}$ & $10.4 \pm 0.96^{\mathrm{c}}$ & 14.7 & 8.0 & $40.22^{\mathrm{a}}$ & 4.42 \\
\hline L.S.D. $5 \%$ & 0.56 & 0.69 & 0.52 & 0.92 & 1.47 & 1.79 & - & - & 5.6 & - \\
\hline
\end{tabular}

T. urticae compared with control. Females on garlic treatment died after 6 days without laying eggs; while males were lived for $4-6$ days, then it were died in garlic treatment. The longevity period was shortened for females treated with plant extracts when compared with untreated females, where it was about 11 days for red pepper, galls and thyme, while seena-L was 13.66 days and untreated females live 14.67 days as mean longevity.

Males longevity differ completely, where it was the shortest when garlic and red pepper used (5.0, 5.67 days) followed by thyme and seena-L ( 8.8 and 9.0 days), ten days in galls treatment; while it was 8.0 days in control under $25^{\circ} \mathrm{C}$ and $60 \% \mathrm{RH}$.
Number of laid eggs by treated females was lower than untreated females, red pepper treated females laid 20.22 eggs with daily rate of 3.25 eggs, increased to 23.82 and 28.8 eggs/ $q$ for seena-L and galls with daily rate of 3.25 and 4 eggs/ + . The lowest egg number was laid by females treated with thyme (13.21 eggs/ + ) and 2.33 as daily rate number. Untreated females laid 40.22 eggs with daily rate of $4.42 \mathrm{eggs} / \mathrm{P}$.

The obtained results are in agreement with that obtained by Bakr (2003) who found that oils of aromatic plants significantly decreased the number of laid eggs. Isman (2000), Enan (2001), and Gokce et al. (2011) reported that plant extracts can affect pest behavior including repelling the pest or prohibiting 
feeding activity, and pest physiology, including molting and respiratory inhibition, growth and fecundity reduction, and also cuticle disruption. Also Waked (2010) found that the plant extracts of Populus euphratica and Fagonia arabica prolonged incubation period of $T$. urticae eggs to 5: 6 days where it was only 3 days in control.

\section{REFERENCES}

Abbott, W.S. 1925. A method of computing the effectiveness of an insecticide. J. Econ. Ent., 18, 265-267.

Abo-Shabana, M. M. A. 1980. Acaricidal action of some new pesticides with special reference to insect growth regulators. Ph.D. Thesis, Fac. of Agric. Zagazig University, 140 pp.

Antonious, G. F.; Meyer, J. E.; Rogers, J. A. and Hu, Y. H. 2007. Growing hot pepper for cabbage looper, Trichopulsia ni (Hubner) and spider mite, Tetranychus urticae (Koch) control. Journal of Environmental Science and Health. Part B, Pesticides, Food Contaminants, and Agricultural Wastes, 42(5): 559-567.

Attia, S.; Grissa, K. L.; Mailleux, A. C., Lognay, G.; Heuskin, S.; Mayoufi, S. and Hance, T. 2012. Effective concentrations of garlic distillate (Allium sativum) for the control of Tetranychus urticae (Tetranychidae). J. Appl. Entomol., 136 (4): 302-312.

Attia, S.; Grissa, K. L.; Ghrabi, G. Z.; Mailleux, A. C.; Lognay, G.; Hance, T. 2012a. Acaricidal activity of 31 essential oils extracted from plants collected in Tunisia. J. Essent. Oil Res., 24: 279288.

Attia, S.; Grissa, K. L.; Lognay, G.; Heuskin, S.; Mailleux, A. C.; Hance, T. 2012 b. Acaricidal activities of Santolina africana and Hertia cheirifolia against Tetranychus urticae (Acari: Tetranychidae). Pest Manag. Sci. doi:10.1002/ps.3269.

Ay, R. 2005. Determination of susceptibility and resistance of some greenhouse populations of Tetranychus urticae Koch to chlorpyrifos (Dursban 4) by the Petri dish-Potter tower method. Journal of Pest Science, 78: 139 - 143.

Bakr, E. M. 2003. Phytochemical and toxicological studies on essential oils of aromatic plants against Tetranychus urticae, Koch. Ph. D. Thesis, Fac. of Agric., Cairo Univ., 150 pp.

Basta, A. and Spooner-Hart, R. N. 2002. Efficacy of an extract of Dorrigo pepper against two-spotted mite and greenhouse thrips. In: Spray oils beyond 2000, Australia. University of Western, Sydney, pp 471-476.

Boyd, D. W. and Alverson, D. R. 2000. Repellency effects of garlic extracts on two spotted spider mite, Tetranychus urticae Koch. J. Ent. Sci., 35(1): 86- 90.

Cavalcanti, S. C. H.; Niculau Edos, S.; Blank, A. F.; Ca^mara, C. A. G.; Arau'jo, I. N. and Alves, P. B. 2010. Composition and acaricidal activity of Lippia sidoides essential oil against two-spotted spider mite (Tetranychus urticae Koch). Bioresour Technol., 101: 829-832.

CoStat 6.400. 2008. Statistical CoHort Software program, Copyright (C) 1998- 2008 CoHort Software 798 Lighthouse Ave. PMB 320 Monterey CA, 93940 USA.

E1-Defrawi, M. E.; Hosny, A.; Toppozda, A. and Hassan, S. 1965. Susceptibility to acaricides of the mite Tetranychus cannabarinus infesting cotton in Egypt. J. Econ. Ent, 58(5): 1106-1110.

Enan, E. 2001. Insecticidal activity of essential oils: octopaminergic sites of action. Comp Biochem Physiol C: Toxicol Pharmacol., 130: 325-337.

Flamini, G. 2003. Acaricides of natural origin, personal experiences and review of the literature (1990-2001). Stud Nat Prod Chem., 28: 381-451.

Flamini, G. 2006. Acaricides of natural origin. Part 2. Review of the literature (2002-2006). Nat. Prod. Commun., 1:1151-1158.

Geng, S.; Chen, H.; Zhang, J. and Tu, H. 2014. Bioactivity of garlic-straw extracts against the spider mites, Tetranychus urticae and $T$. viennensis. Ournal of Agricultural and Urban Entomology, 30(1): 38-48.

Georghiou, G. P. 1972. The evolution of resistance to pesticides. Annual Review of Ecology and Systematics, 3: 133-168.

Gokce, A.; Isaacs, R. and Whalon, M. E. 2011. Ovicidal, larvicidal and antiovipositional activities of Bifora radians and other plant extracts on the grape berry moth Paralobesia viteana (Clemens). J. Pest. Sci., 84: 487-493.

Heikal, H. M. M.; Abd-Elhady, H. K. and Edrees N. O. 2012. Composition and acaricidal activities of Lavandula officinalis essential oil against Tetranychus urticae (Acari: Tetranychidae). Minufiya J. Agric. Res.,37(1): 221 - 230.

Isman, M. B. 2000. Plant essential oils for pest and disease management. Crop Prot., 19: 603-608.

Isman, M. B. 2001. Pesticides based on plant essential oils for management of plant pests and diseases. In: symposium on development of natural pesticides from forest resources. Republic of Korea, Seoul, pp 1-9.

Isman, M. B. 2004. Plant essential oils as green pesticides for pest and disease management. ACS Symp Ser, 887: 41-51.

Isman, M. B. 2006. The role of botanical insecticides, deterrents and repellents in modern agriculture and an increasingly regulated world. Annl Rev Entomol., 51: 45-66. 
Jedrychowski, R.A. 1991. Probit Analysis Program, (PROBAN) version 1.1.

Kotb, M. S. A. 2003. Toxicity and Biological effects of some plant extracts on phytophagous and predaceous mites. M. Sc. Fac. of Agric., ElFayoum, Cairo University, $155 \mathrm{pp}$.

Mutwally, H.M.A.; Omar, M.A. and Bedaiwy, M. 2002. Microsporum gallinae growth response to some plant extracts. Faculty of Applied Science, Umm Al-Qura University, Makkah, Kingdom of Saudi Arabia pp.1-8.

Nour El-Deen, M. M. and Abdallah, A. M. 2013. Effect of different compounds against Tetranychus urticae Koch and its predatory mite Phytoseiulus persimilis A.-H. under laboratory conditions. J. Appl. Sci. Res., 9: 39653973.

Pontes, W. J. T.; de Oliveira, J. C. S.; da Camara, C. A. G.; Lopes, A.; Junior, M. and de Oliveira, J.V. 2007. Composition and acaricidal activity of the resin's essential oil of Protium bahianum Daly against the two-spotted spider mite (Tetranychus urticae). J Essent Oil Res., 19: 379-389.

Pontes, W.; Silva, J.; Da Camara, C.; Gondim-Junior, M.; Olivera, J. and Schwartz, M. 2010. Chemical composition and acaricidal activity of the essential oils from fruits and leaves of Protium bahianum Daly. J. Essent. Oil. Res., 22: 279-282.

Potenza, M. R.; Tackermatsu, A. P. and Bendicto, L. H. 1999. Evaluation of plant extracts on the control of Tetranychus urticae Koch, (Acari: Tetranychidae) in laboratory conditions. Arquivos do Institwto Biologico Sao Paule, 66(2): 91-97.

Rasikari, H. L.; Leach, D. N.; Waterman, P. G.; Spooner-Hart, R. N.; Basta, A. H. and Banbury, L.
K. 2005. Acaricidal and cytotoxic activities of extracts from selected genera of Australian Lamiaceae. J. Econ. Entomol., 98: 1259-1266.

Steiner, M.Y.; Spohr, L.J. and Goodwin, S. 2011. Impact of two formulations of the acaricide bifenazate on the spider mite predator Phytoseiulus persimilis Athias-Henriot (Acari: Phytoseiidae). Aust. J. Entomol., 50: 99-105.

Stumpf, N.; Zebitz, C. P. W.; Kraus, W.; Moores, G. D. and Nauen, R. 2001. Resistance to organophosphates and biochemical genotyping of Acetylcholinesterases in Tetranychus urticae (Acari: Tetranychidae). Pest Biochem Physiol., 69: 131-142.

Tewary, D. K.; Bhardwaj, A. and Shanker, A. 2005. Pesticidal activities in five medicinal plants collected from mid hills of western Himalayas. Ind. Crop Prod., 22: 241-247.

Tirello, P.; Pozzebon, A.; Cassanelli, S.; Van Leeuwen, T. and Duso, C. 2012. Resistance to acaricides in Italian strains of Tetranychus urticae: Toxicological and enzymatic assays. Exp. Appl. Acarol., 57:53-64.

Van Leeuwen, T.; Van Pottelberge S.; Nauen R. and Tirry L. 2007. Organophosphate insecticides and acaricides antagonise bife-nazate toxicity through esterase inhibition in Tetranychus urticae. Pest Manag. Sci.., 63: 1172-1177.

Waked, D. A. A. 2010. Environmintal aspects for using some selected natural extracts in controlling certain pests to enhance biological control. Ph. D. Fac. of Agric., Zagazig, University, Egypt, 125 pp.

Zhang, Z. Q. 2003. Mites of greenhouses: Identification, biology, and control. $\mathrm{CAB}$ International Publishing, UK., 244 pp. 